After Treatment.-The bladder was washed out with a tepid solution of boracic acid. The wound was antiseptically treated (painted with iodoform and eucalyptus oil), and left open. The animal micturated soon after the operation, and passed urine both through the wound and along the natural passage. The passage through the wound

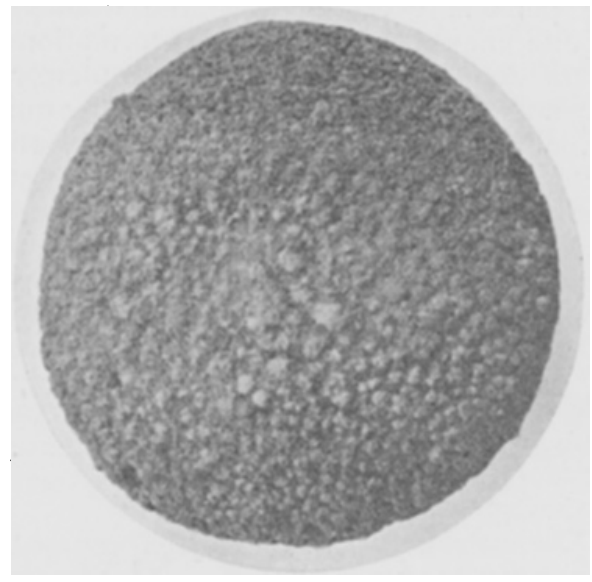

Cystic calculus (natural size).

ceased after the first day of the operation-27th January I90I. The wound is being daily dressed antiseptically with what I call antiseptic emulsion, composed of boracic acid, carbolic acid, jodoform, eucalyptus oil, and glycerine, and satisfactory progress continues to be made. The wound is two inches in length and a quarter of an inch deep.

\title{
AN INTERESTING BOG-SPAVIN CASE TREATED BY FREE INCISION AND NEURECTOMY.
}

By Fred. Hobday, F.R.C.V.S., London.

IN June last I was consulted by Mr E. R. Harding, M.R.C.V.S., regarding a valuable Cleveland bay mare, six years old, suffering acute lameness from the presence of an enlarged hock. The latter showed a bog-spavin and thorough-pin, making the joint quite as big as an ordinary football and very tense. The mare was in a lot of pain, and continually rested the leg.

On the $4^{\text {th }}$ of June an aspirator was applied, some of the fluid being drawn away, and a solution of iodine and chinosol in water injected. Temporarily there was an improvement in appearance, but the lameness was as great as ever, and a second operation was decided upon.

On the 2 oth of July, under strict antiseptic precautions and with the aid of chloroform, an incision fully 3 inches in length was made 
right into the true hock joint. A very large quantity of synovia, including nine or ten coagulated Jumps, escaped. The interior was carefully swabbed out with chinosol lotion and boiled wadding, and plugged before the patient was allowed to get up. Digital examination of the interior and exterior of the joint now revealed enlargements which were not perceptible before.

$\mathrm{Mr}$ Harding personally attended to the wound afterwards, and recovery was quite uneventful and without formation of pus.

On the I 8 th of August the wound had completely healed, and the hock was very much reduced in size, in fact by quite one-half, but the exostoses could still be felt, and the mare was still lame.

On this date peroneal and posterior tibial neurectomies were performed, and the animal became practically sound at once.

As soon as the wound healed she was sent to work, and is still working regularly, and quite sound. The hock is now, Mr Harding informs me, not more than a quarter the size it was before the operation; in fact, the inside where the incision was made is practically normal.

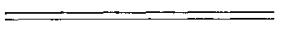 \\ Gustracts and 密epurts. \\ THE PERIOD OF INCUBATION IN TUBERCULOSIS, AND THE AGE OF TUBERCULOUS LESIONS.}

AT the instigation of the Société de Médicine Vétérinaire Pratique, a committee was appointed in France early last year to carry out experiments that might throw light on the period of incubation in tuberculosis in cattle, and the age of tuberculous lesions as indicated by their appearance. For this purpose a sum of 2000 francs was placed at the disposal of the committee, and the experiments were begun in May last. The general plan of the experiments was to submit the animals to a preliminary test with tuberculin, in order to ascertain that they were not already the subjects of naturally contracted tuberculosis; to then infect them in different ways with the disease, and afterwards test them at intervals of six days with tuberculin. Finally, the animals were to be killed and submitted to post-mortem examination. The following is condensed from the report of the experiments made by MM. Nocard and Rossignol :--

Infection by Feding. - The animals of this lot, numbered I, 2, 3, and 4, were submitted to gastro-intestinal infection. On the 8th May an attempt was made to infect them by giving to each 475 grammes of finely divided pleural tubercles mixed with some bran. Only one of the animals, No. 3, consumed the whole of its portion; No. 2 took about 100 grammes of a tuberculous emulsion mixed with about three litres of water. On the $\mathrm{r} 4^{\text {th }}$ May a further attempt was made to infect Nos. I, 2, and 4 by giving to each of them $25^{\circ}$ grammes of tissue from a tuberculous mediastinal gland, and of other tuberculous material in the way of softening. The tuberculous tissue was finely minced, mixed with water, and administered by means of a bottle.

As in the other cases, the animals were tested with tuberculin on the $4^{\text {th }}$ May, and every six days afterwards. It was not until the thirty-second day 